\title{
DOCTRINA \\ La invalidación impropia: control administrativo y judicial de una resolución de calificación ambiental
}

\author{
The Invalidation Review: Administrative \\ and Judicial Review of Environmental Permits
}

\author{
Jaime Phillips Letelier (iD) \\ Universidad Finis Terrae, Chile
}

\begin{abstract}
RESUMEN Este artículo analiza la llamada teoría de la «invalidación impropia», formulada para orientar la aplicación del artículo 17 núm. 8 de la Ley 20.600, a la luz de la tensión entre precaución ambiental y protección de la certeza jurídica. Se constata que la mencionada teoría privilegia en gran medida la estabilidad de las resoluciones de calificación ambiental en desmedro de los derechos e intereses de terceros, ya que esta teoría solo permite a los terceros ajenos al procedimiento de evaluación ambiental impugnar una resolución de calificación ambiental en un plazo de treinta días desde su notificación a quienes sí participaron en el procedimiento. Considerando lo anterior, el artículo ofrece tres argumentos para descartar la teoría de la invalidación impropia: uno de legalidad, otro de supletoriedad normativa y uno de acceso a la justicia. En forma adicional, se argumenta que tal teoría no ofrece un equilibrio adecuado de los intereses en juego en esta materia. Luego se defiende la aplicación supletoria íntegra del artículo 53 de la Ley 19.880 en relación con el artículo 17 núm. 8 de la Ley 20.600, de manera que los terceros ajenos al procedimiento de evaluación puedan solicitar la invalidación de una resolución de calificación ambiental en un término de dos años desde su dictación. Finalmente, se propone un modo de equilibrar los intereses en juego aplicando las ideas de protección de la confianza y de situaciones jurídicas consolidadas.
\end{abstract}

PALABRAS CLAVE Invalidación, resolución de calificación ambiental, estabilidad, confianza legítima.

ABSTRACT This article discusses the so-called «invalidation review» theory, formulated to orient the application of article 17 number 8 of Law 20,600 through the lens of the tension between environmental precaution and the protection of legal certainty. It is noted that the forementioned theory largely favours the stability of environmental 


\begin{abstract}
permits to the detriment of the rights and interests of third parties, because this theory only allows third parties outside the environmental assessment procedure to challenge an environmental permit within 30 days from its notification to those who did participate in the procedure. Considering this, the article offers three arguments to discard the «invalidation review» theory: one concerned with the legality of such approach, one with the integration of special norms with general norms and one related to the access to justice. In addition, it is argued that such theory does not offer an adequate balance of the interests at stake in this matter. Then it argues for the full supplementary application of article 53 of Law 19,880 in relation to article 17 number 8 of Law 20.600, so that third parties outside the environmental assessment procedure may request the invalidation of an environmental permit within two years from its issuance. Finally, a way of balancing the interests at stake is proposed by applying the doctrine of legitimate expectation.
\end{abstract}

KEYWORDS Annulment, environmental permits, stability, legitimate expectations.

\title{
Introducción
}

Uno de los mayores anhelos de todo sistema de evaluación de impacto ambiental es lograr «certeza jurídica» tanto para los titulares de los proyectos como para las comunidades afectadas por estos (Carrasco, 2018: 7). La realización de este ideal implica que el sistema tenga resultados previsibles y que las decisiones tomadas gocen de estabilidad (Ávila, 2016: 67-69). Pero, dada la naturaleza de nuestro sistema de evaluación ambiental, lo anterior no es fácil de conseguir. El artículo 10 de la Ley 19.300 enumera una lista de proyectos que deben someterse a evaluación ambiental en la medida que sean «susceptibles de causar impacto ambiental». En virtud de lo anterior, una resolución de calificación ambiental que no considera todos los impactos relevantes está expuesta a ser declarada nula por infracción a la citada norma.

Para evitar esto, es importante que en todo procedimiento de evaluación se identifiquen todos los eventuales impactos que un proyecto puede causar. Esto se debe hacer a través de la información suministrada por el titular del proyecto, por medio de las pesquisas y análisis que realice la autoridad ambiental, y a través de los procedimientos de participación que contempla la legislación. Sin embargo, no es infrecuente que terceros que no han participado en el procedimiento soliciten la invalidación o impugnen judicialmente una resolución de calificación ambiental que ha comenzado a producir efectos jurídicos, alegando la existencia de impactos no considerados en el procedimiento de evaluación.

Lo dicho hasta ahora me permite conectar este problema con el control de legalidad de los actos de carácter ambiental. Este artículo analizará en qué condiciones es posible que el Servicio de Evaluación Ambiental invalide una resolución de calificación ambiental a solicitud de terceros ajenos al procedimiento de evaluación ambiental. De este modo, este trabajo no analizará la eventual aplicación que podría tener en 
este tipo de casos el artículo 25 quinquies de la Ley 19.300, sino que se centrará en la posibilidad de invalidar una resolución de calificación ambiental y el posterior control judicial de tal decisión. Esto porque la mencionada potestad parece estar referida a la posibilidad de modificar una resolución de calificación ambiental válidamente emitida, respecto de variables evaluadas y contempladas en el plan de seguimiento; lo que plantea interesantes preguntas que exceden el objeto de este trabajo (como la de si podría ser objeto de revisión una resolución de calificación ambiental con vicios de juridicidad antes o después de transcurrido el plazo para invalidar), que merecen un estudio particular. Asimismo, tampoco se analizará la eventual aplicación que podría tener el artículo 6o de la Ley 19.880 que consagra el denominado «recurso extraordinario de revisión», pues la aplicación de esta norma también plantea problemas que ameritan un estudio particular, como el de qué implica un «debido emplazamiento» de los terceros ajenos al procedimiento de evaluación o en qué consistiría un «manifiesto error de hecho» al dictar una resolución de calificación ambiental.

En el contexto mencionado, el artículo 17 núm. 8 de la Ley 20.600 contiene una norma que permite impugnar ante un tribunal ambiental la decisión que resuelve el procedimiento de invalidación de un acto de carácter ambiental. La Corte Suprema ha sostenido que esta norma debe ser completada con el artículo 53 de la Ley 19.880, que consagra la potestad de invalidación de los órganos administrativos. De esta manera, el procedimiento de invalidación de que habla el artículo 17 núm. 8 de la Ley 20.600 es el regulado en el artículo 53 de la Ley 19.880. Por tanto, la Administración podría invalidar un acto de carácter ambiental dentro del plazo de dos años.

Sin embargo, al interior de la Corte Suprema se ha desarrollado otra línea jurisprudencial: la de la llamada teoría de la invalidación impropia. Según este planteamiento, el artículo 17 núm. 8 regula un mecanismo de impugnación de actos de carácter ambiental que consiste en un recurso administrativo que se interpone ante la misma autoridad ambiental para reclamar de la legalidad de un acto de carácter ambiental, cuyo ejercicio es requisito para interponer la acción judicial que la citada norma contempla para impugnar tal tipo de decisiones ante el tribunal ambiental respectivo. Así, se trata de un recurso administrativo destinado a reclamar la legalidad ante la propia autoridad que lo dictó, el cual constituye un trámite cuyo agotamiento previo es necesario para impugnar la decisión ante el tribunal ambiental dentro de los treinta días.

Por esto, se habla de que es un «recurso de invalidación», de ahí el nombre de invalidación impropia. En consecuencia, para solicitar la nulidad mediante este recurso de invalidación se tiene un plazo de treinta días. Luego de ese plazo, la autoridad ambiental podría invalidar dentro de los dos años del artículo 53 de la Ley 19.880, pero solo se podría acceder a la vía judicial si el órgano resuelve invalidar, no si se niega a tal posibilidad, ya que tal norma no permite la impugnación judicial del acto que deniega la solicitud de invalidación. 
Tratándose de una resolución de calificación ambiental, la adopción de una u otra postura genera importantes diferencias. El amplio plazo de dos años para solicitar la invalidación puede ser visto como un atentado a la seguridad jurídica, pues no existiría certeza sobre la estabilidad de una resolución de calificación ambiental hasta que este estuviese vencido. De este modo, la segunda teoría desarrollada por la Corte Suprema puede resultar razonable: por regla general, el plazo para impugnar una resolución de calificación ambiental y acceder al tribunal ambiental debiese ser uno breve de treinta días, salvo que el propio órgano acceda a invalidar su decisión dentro del plazo de dos años previsto en el artículo 53 (Bordalí y Hunter, 2020: 176-178).

No obstante, esta solución tiene sus propios problemas. El plazo breve de impugnación podría dejar en la indefensión a terceros que no participaron en el procedimiento de evaluación ambiental, quienes no cuentan con legitimación expresa para impugnar una resolución de calificación ambiental en la Ley 20.6oo, pero que sí podrían ostentar derechos o intereses que los legitimen para actuar en los términos del artículo 21 de la Ley 19.880 (Bordalí y Hunter, 2020: 181-182). ${ }^{1}$ Estos terceros se enterarían de la existencia de la resolución de calificación ambiental que les causa agravio al comenzar la ejecución del proyecto. De este modo, siendo la invalidación impropia la única vía disponible para la protección de sus intereses (Bordalí y Hunter, 2020: 171-172), el breve plazo de treinta días haría prácticamente imposible que reciban protección. En ese caso, la única posibilidad de estos terceros de conseguir tutela de su derecho a vivir en un medio ambiente libre de contaminación sería una vía que es de exclusivo resorte de la autoridad administrativa, quedando privados del acceso al tribunal ambiental si el Servicio de Evaluación Ambiental no decide invalidar su decisión.

La compleja redacción de la regla del artículo 17 núm. 8 de la Ley 20.600 ha permitido que los tribunales moldeen su aplicación a la medida de los distintos casos particulares que se presentan (Carrasco y Benítez, 2017: 120). De este modo, se ha privilegiado la estabilidad de las resoluciones de calificación ambiental o la precaución aplicando una u otra teoría. En este contexto, en este artículo me propongo argumentar por qué se debiese abandonar la teoría de la invalidación impropia y, en lugar de ello, entender que los terceros ajenos al procedimiento de evaluación ambiental pueden solicitar la invalidación de una resolución de calificación ambiental en el plazo de dos años ante la autoridad ambiental, y que la resolución que pone término a ese procedimiento abre, se disponga o no la invalidación, la posibilidad de reclamar la decisión ante el tribunal ambiental. Esto por razones de legalidad; de especialidad y supletoriedad normativa, y por razones de acceso a la justicia.

1. En adelante, para referirme a estos terceros ajenos al procedimiento de evaluación ambiental y que no gozan de legitimación expresa en la Ley 20.600 pero sí según la Ley 19.88o, hablaré de «terceros ajenos al procedimiento de evaluación» o simplemente de «terceros». 
Con lo anterior, se debiese aceptar como regla general el plazo de dos años para que la autoridad ambiental invalide una resolución de calificación ambiental. Ahora bien, la invalidación de un acto administrativo tiene, por regla general, efecto retroactivo o ex tunc. Esto se debe a que la invalidación de un acto administrativo, tal como ocurre con la nulidad de derecho público (Valdivia, 2009: 868), implica una declaración de nulidad que, por su naturaleza, tiene efecto retroactivo, pues solo se limita a restablecer la juridicidad quebrantada; de modo que se trata de un acto al que no le resulta aplicable la prohibición del artículo 52 de la Ley 19.880 (Valdivia, 2018: 197-198, 240-242; Phillips, 2020: 92-99).

En estas circunstancias, la tesis que defiendo nos conduce a una solución que puede ser criticada pues brinda poca seguridad jurídica a los titulares de los proyectos. Frente a esto, argumentaré que la autoridad administrativa puede moderar los efectos en el tiempo de la declaración de nulidad de una resolución de calificación ambiental como forma de proteger las expectativas generadas por el acto nulo y evitar perjuicios al titular del proyecto. Para esto, construiré una regla flexible que permitirá proteger al particular con distintos mecanismos: la convalidación de la resolución de calificación ambiental viciada, la adaptación de la resolución de calificación ambiental o la indemnización de perjuicios. Se propondrá que estos mecanismos sean utilizados teniendo en cuenta la intensidad de las eventuales afectaciones al medio ambiente, los intereses de terceros y el interés del titular del proyecto afectado.

Este artículo tendrá la siguiente estructura. En un primer apartado se explicarán con detalle las dos posturas sobre el plazo para invalidar un acto de carácter ambiental. Primero, aquella que entiende que cualquier procedimiento de invalidación iniciado conforme con el artículo 53 de la Ley 19.880 da lugar a la reclamación judicial del artículo 17 núm. 8 de la Ley 20.600. Segundo, se explicará la llamada teoría de la invalidación impropia y sus fundamentos. Para terminar, se mostrará cómo la primera postura privilegia la precaución en materia medioambiental mientras que la segunda privilegia la estabilidad de las autorizaciones ambientales.

En el segundo apartado se formularán tres críticas a la teoría de la invalidación impropia. La primera, que la teoría de la invalidación impropia es contraria al principio de legalidad y al texto del artículo 17 núm. 8 de la Ley 20.600. La segunda que la mencionada teoría utiliza de un modo incoherente las técnicas de supletoriedad y de especialidad de la ley. La tercera que la idea de invalidación impropia afecta el derecho a la tutela judicial efectiva y limita de modo injustificado el acceso a los tribunales ambientales. Luego, se hará una reflexión sobre los intereses en juego al optar por una u otra teoría y qué elementos se debiesen tener en cuenta para proveer una solución a este problema.

Por último, en el tercer apartado se planteará cómo proteger la certeza jurídica en un contexto en que es posible invalidar administrativamente una resolución de calificación ambiental dentro del plazo de dos años desde su notificación. Para esto 
se analizará el rol que puede caberle en ello al principio de protección de la confianza y a la jurisprudencia de la Contraloría General de la República sobre situaciones jurídicas consolidadas. Se argumentará que dar efecto ex tunc a la invalidación de una resolución de calificación ambiental puede atentar contra la libertad económica de los particulares, dada la influencia que una autorización ambiental puede tener sobre la toma de decisiones de los particulares. Por esto, se propondrán tres posibles cursos de acción que la autoridad puede tomar para compatibilizar libertad económica con la necesidad de invalidar una resolución de calificación ambiental contraria a derecho. Al final se expondrán las principales conclusiones del trabajo.

\section{Invalidación impropia y estabilidad de las resoluciones de calificación ambiental}

De la historia legislativa del artículo 17 núm. 8 de la Ley 20.600 se puede concluir que el propósito de la norma era crear un reclamo de legalidad en contra de actos ambientales de carácter general, pero con el requisito previo de haber solicitado la invalidación del acto ante la autoridad ambiental (BCN, 2012: 264-278). De este modo, se permite recurrir ante el tribunal ambiental a los interesados en el procedimiento de evaluación ambiental y a los terceros afectados en sus intereses por una autorización ambiental; aunque también se quiso evitar fomentar de un modo excesivo la interposición de acciones ante los tribunales ambientales, por lo que se consagró la exigencia de que el particular solicitase en forma previa la invalidación del acto ante la autoridad administrativa (Barros y Valdivia, 2019: 144).

Frente a esto, en un primer momento, se entendió por «procedimiento administrativo de invalidación» cualquiera en el que se cuestionara la legalidad de un acto administrativo de carácter ambiental, ya sea un recurso administrativo o una solicitud de invalidación conforme con el artículo 53 de la Ley 19.880. Así, la Corte Suprema ha entendido que los terceros ajenos al procedimiento de calificación ambiental pueden solicitar la invalidación de una resolución de calificación ambiental dentro del plazo de dos años, pudiendo incluso la autoridad resolver fuera de ese plazo si la invalidación fue solicitada dentro del término de dos años desde la publicidad del acto, y luego impugnar la decisión ante el tribunal ambiental respectivo. ${ }^{2}$

No obstante, esta solución ha sido criticada. Al respecto, se ha esgrimido que es lesiva de la estabilidad de los actos administrativos como manifestación de la seguridad jurídica: nadie comenzaría la ejecución de un proyecto autorizado sino hasta que hubiese transcurrido el mencionado plazo (Barros y Valdivia, 2019: 146). Ahora bien, convive con la línea jurisprudencial anteriormente descrita, otra de la misma Corte

2. Corte Suprema, rol 31.176-2016, 25 de julio de 2017, considerando séptimo; Corte Suprema, rol 45.806-2016, 6 de julio de 2017, considerando octavo. 
Suprema. Se trata de la teoría denominada de la invalidación impropia. Este planteamiento tiene su origen en una opinión concurrente del entonces ministro Pierry, ${ }^{3}$ pero que en forma posterior ha sido acogido por la mayoría de la Corte Suprema y por los tribunales ambientales (Bordalí y Hunter, 2020: 172-178; Riestra, 2019: 37-39; Barros y Valdivia, 2019: 149-151). ${ }^{4}$

La teoría contemplada en los fallos citados sostiene que el artículo 17 núm. 8 consagra dos recursos. Primero, un recurso jurisdiccional contemplado en forma explícita para impugnar decisiones de carácter ambiental dentro de los treinta días desde que se resuelva un procedimiento administrativo de invalidación. Segundo, un recurso administrativo para solicitar la invalidación de un acto de carácter ambiental, que es distinto de la potestad de invalidación del artículo 53 de la Ley 19.880. Este último recurso estaría implícito en la Ley 20.600 y sería de aquellos recursos administrativos que es necesario agotar antes de acceder a la vía judicial primeramente mencionada, tal como ocurre respecto del reclamo de ilegalidad municipal (Bordalí y Hunter, 2020: 175).

El plazo para interponer este recurso sería de treinta días. Esto porque, dándole una mirada sistemática al sistema de impugnaciones regulado en la Ley 20.600, es posible observar que el legislador ha optado por establecer un trámite de agotamiento previo de la vía administrativa antes de permitir el acceso a la jurisdicción ambiental. Y este trámite consiste en la interposición de un reclamo de carácter administrativo cuyo plazo de interposición es, invariablemente, de treinta días. Tal es el caso, por ejemplo, de los artículos 17 números 5 y 6 de la Ley 20.600, normas que hacen referencia a los recursos administrativos de la Ley 19.300.

Por esto, se debiese entender que, al crear el recurso judicial del artículo 17 núm. 8 , la intención del legislador fue la de supeditar el ingreso a esa vía a la interposición previa de un recurso de legalidad administrativo (denominado «de invalidación impropia») dentro de los treinta días siguientes a la notificación o publicación de la decisión impugnada. Siguiendo con esta teoría, la autoridad ambiental podría ejercer su potestad de invalidación propiamente tal dentro de los años desde que el acto haya recibido la debida publicidad, pues la invalidación y este recurso de invalidación corresponderían a potestades distintas. En el caso de que la autoridad decida invalidar por esta vía, el acto invalidatorio será reclamable ante el tribunal ambiental, por disponerlo expresamente el inciso final de la norma. Sin embargo, en el caso de

3. Corte Suprema, rol 23.00o-2014, 22 de abril de 2015, prevención.

4. Corte Suprema, rol 8737-2018, 12 de marzo de 2020, considerando decimosexto; Corte Suprema, rol 11.512-2015, 12 de mayo de 2016, considerando décimo; Corte Suprema, rol 16.263-2015, 16 de agosto de 2016; Primer Tribunal Ambiental, rol R-20-2019, 26 de julio de 2019, considerando 23. ${ }^{\circ}$; Tercer Tribunal Ambiental, R-53-2017, considerando decimosexto; Primer Tribunal Ambiental, R-33-2019, 5 de octubre de 2020 , considerando decimoctavo. 
que la autoridad no diese lugar a la invalidación, el acto no sería impugnable por no contemplar el artículo 53 de la Ley 19.880 esa posibilidad.

Teniendo en cuenta lo anterior, si la interpretación que permitía impugnar ante un tribunal ambiental cualquier acto que resuelva un procedimiento invalidatorio (ya sea que ordene la invalidación o la deniegue) era criticable por sacrificar la seguridad jurídica en desmedro de la estabilidad de las autorizaciones ambientales, lo opuesto puede ser dicho respecto de la tesis de la invalidación impropia: esta última posición privilegia en gran medida la estabilidad de los actos administrativos ambientales, en desmedro de la precaución ambiental. Esto porque una resolución de calificación ambiental dictada en contravención al artículo 10 de la Ley 19.300 por no haber evaluado determinados impactos ambientales presumiblemente no podría ser invalidada luego del transcurso de ese breve plazo de treinta días, por haber operado la preclusión. En efecto, el transcurso de treinta días desde la notificación o publicación del acto cierra toda posibilidad de impugnar judicialmente el acto ante los tribunales ambientales, salvo que la misma autoridad que lo dictó acceda a invalidarlo dentro de los dos años previstos en el artículo 53 de la Ley 19.880 .

Lo anterior puede no ser complejo para quienes participaron del procedimiento de evaluación ambiental, pero sí afecta a los terceros que pueden ver lesionados en sus intereses por estas decisiones: a ellos solo les queda acudir a la invalidación y solo podrían acceder el tribunal ambiental en la medida en que la autoridad administrativa acceda a invalidar el acto; de lo contrario, no quedaría ulterior recurso. Por otro lado, existe una corriente importante en la doctrina y la jurisprudencia que señala que los terceros tampoco podrían optar por acciones contencioso-administrativas generales como la nulidad de derecho público o el recurso de protección. Ya era raro que los tribunales ordinarios de justicia acogiesen una nulidad de derecho público antes de la Ley 20.600 (Cordero, 2013: 514-515); pues bien, menos lo sería ahora a la luz del denominado principio de especialidad de la acción desarrollado por la Corte Suprema. ${ }^{5}$ A su vez, los recursos de protección han experimentado un declive en lo que se refiere a la impugnación de actos administrativos ambientales, desde la implementación de los recursos administrativos y acciones especiales de la Ley 20.600 (Bordalí y Hunter, 2020: 55; Zúñiga, 2015: 38-39).

Mirando el problema desde la óptica de un acto autorizatorio como es la resolución de calificación ambiental, la tesis de la invalidación impropia tiene sus virtudes y costos: su virtud consiste en que brinda mayor estabilidad a las resoluciones de calificación ambiental y seguridad a los titulares de los proyectos; el costo es limitar las posibilidades que tienen los terceros ajenos al procedimiento de evaluación de acceder a la justicia ambiental (Bordalí, 2019: 26).

5. Corte Suprema, rol 18.766-2019, 29 de enero de 2020, considerando séptimo; Corte Suprema, rol 34-277-2017, 7 de marzo de 2019, considerando décimo. 


\section{Invalidación impropia: objeciones}

En este apartado se argumentará por qué debemos descartar la tesis de la invalidación impropia y optar por una interpretación más bien literal del artículo 17 núm. 8 de la Ley 20.600. Para esto, ofreceré tres argumentos: primero, cuestionaré la conformidad al principio de juridicidad de la tesis mencionada; segundo, mostraré que la tesis de la invalidación impropia aplica de manera incoherente los principios de especialidad y supletoriedad de la ley; y, tercero, cuestionaré la tesis de la invalidación impropia desde el punto de vista de las garantías constitucionales de acceso a la jurisdicción y de protección de un medio ambiente libre de contaminación.

Luego presentaré un argumento que podría formularse en favor de la tesis de la invalidación impropia, consistente en que esta postura logra un mejor equilibrio entre revisión y estabilidad de las resoluciones de calificación ambiental. Sin embargo, lo descartaré arguyendo que, si se consideran todos los intereses en juego, la teoría de la invalidación impropia favorece en exceso el interés fiscal de la autoridad administrativa (en el sentido de no verse expuesta a demandas destinadas a hacer valer su responsabilidad patrimonial) y el interés del desarrollador del proyecto, en desmedro del interés público y el interés de los terceros afectados. Por esto, para dar la debida consideración a todos los intereses involucrados en estos asuntos, argumentaré en favor de la necesidad de aplicar una regla más flexible para determinar los efectos en el tiempo de la invalidación de una resolución de calificación ambiental.

\section{Legalidad de la tesis de la invalidación impropia}

Desde el punto de vista de la legalidad, la tesis de la invalidación impropia tiene dos dificultades. La primera es que la mencionada postura tiene por establecida una potestad implícita cuya existencia se deriva del texto del artículo 17 núm. 8 de la Ley 20.60o: del hecho de que exista una acción para impugnar ante el tribunal ambiental los actos que resuelven procedimientos invalidatorios, se deriva que los particulares tienen la opción de interponer un «recurso de invalidación» dentro de treinta días, y el Servicio de Evaluación Ambiental tiene, a su vez, la potestad de conocer y resolver dicho recurso.

Lo anterior es cuestionable de cara al principio de juridicidad consagrado en el artículo 7 de la Constitución, en relación con que nadie tiene «otra autoridad o derechos que los que expresamente se les hayan conferido en virtud de la Constitución o las leyes». Nuestro sistema jurídico no tolera la existencia de potestades implícitas (Soto Kloss, 2012: 177-178), como sí ocurre en otros sistemas (Valdivia, 2018: 146-147). De este modo, al no estar contenida en la ley en forma expresa la posibilidad de interponer este recurso ni la potestad para resolverlo, es posible concluir que no se ajusta a derecho la teoría de la invalidación impropia. Y en nada ayuda al planteamiento de 
la «invalidación impropia» el que los números 5 y 6 del artículo 17 de la Ley 20.600 hayan hecho referencia a reclamos administrativos especiales, pues de que el legislador haya regulado tal mecanismo de impugnación en otros casos, ello no significa que tal cuestión deba ser extrapolada al artículo 17 núm. 8 en ausencia de una norma legal expresa.

Una segunda dificultad tiene que ver con la letra del artículo 17 núm. 8. Tal norma señala que son impugnables ante los tribunales ambientales los actos que resuelven un "procedimiento administrativo de invalidación». Considerando lo anterior, se ha señalado que la «jurisprudencia ha llegado al extremo de negar que una solicitud de invalidación fundada en el artículo 53 de la LBPA [Ley de Bases de Procedimiento Administrativo] y no en el artículo 17 núm. 8 LTA [Ley de Tribunales Ambientales] configure un 'procedimiento administrativo de invalidación' cuya resolución pueda reclamarse ante los TTAA [Tribunales Ambientales]» (Barros y Valdivia, 2019: 150; cf. Carrasco y Benítez, 2017: 111). Así, la Corte Suprema ha sostenido que una solicitud de invalidación de una resolución de calificación ambiental con soporte en el artículo 53 de la Ley 19.880 no es un acto que resuelva un procedimiento de invalidación de un acto de carácter ambiental. ${ }^{6}$

Esto último es discutible. Aunque se considere que existe un recurso de invalidación implícito en la Ley 20.600, no se observa cómo un procedimiento iniciado conforme con el artículo 53 de la Ley 19.880 no cumpliría con el requisito de ser un «procedimiento administrativo de invalidación» (Bordalí, 2019: 25): el supuesto de hecho previsto en la norma (la existencia de una resolución que resuelve un procedimiento administrativo de carácter ambiental) encaja perfectamente con lo que un órgano hace cuando ejerce su potestad del artículo 53 de la Ley 19.880 cuando esta se refiere a actos dictados por autoridades con competencia ambiental. En este sentido, aunque se admita que el principio de legalidad tolera la existencia de este reclamo de legalidad implícito, la tesis de la invalidación impropia no explica cómo es que la vía del artículo 53 de la Ley 19.880 no activa el acceso a la acción judicial prevista en el artículo 17 núm. 8 de la Ley 20.600.

\section{Especialidad y supletoriedad}

La tesis de la invalidación impropia propone que el artículo 17 núm. 8 es una norma de carácter especial que regula la impugnación administrativa y judicial de los actos que resuelven procedimientos de invalidación de actos de carácter ambiental. Este carácter especial tiene una importante consecuencia. El artículo 17 núm. 8 regula un recurso administrativo especial y su posterior reclamación judicial ante los tribunales ambientales. De este modo, tal norma nada tendría que ver con la invalidación regu-

6. Corte Suprema, 16 de agosto de 2016, rol 16.263-2015, letra N. 
lada en el artículo 53 de la Ley 19.880. Dado que el artículo 17 núm. 8 de la Ley 20.600 consagra un recurso administrativo especial implícito, no procedería integrar esta norma con aquella general que consagra la potestad de invalidación. De este modo, es preciso distinguir entre la invalidación general prevista en el artículo 53 de la Ley 19.880 y la «invalidación impropia» del artículo 17 núm. 8 de la Ley 20.600.

A pesar de que lo dicho en el párrafo anterior parece lógico, tal idea no es del todo coherente. Esta teoría aplica de un modo ambivalente el principio de especialidad de las leyes en relación con la Ley 20.600 y el principio de supletoriedad contenido en la Ley 19.88o. Para entender esto es útil considerar los tres grados en que la Ley 19.880 puede tener carácter de supletoria.

Según Cordero, un primer grado de supletoriedad se da cuando el legislador no regula un procedimiento específico para el ejercicio de una potestad. En ese caso el procedimiento queda regulado en forma íntegra por las normas y principios de la Ley 19.880. Continúa diciendo este autor que un segundo grado se da cuando el legislador regula un procedimiento administrativo en forma parcial, situación en la cual el procedimiento quedará regulado por sus propias normas especiales, y supletoriamente por las normas de la Ley 19.880 que corresponda aplicar y sus principios. Siguiendo el mismo planteamiento, en tercer lugar, cuando el legislador regula en forma íntegra un determinado procedimiento, se deben aplicar sus propias normas, y los principios de la Ley 19.880 solo se podrán usar como criterio interpretativo o como principios generales para resolver casos concretos (Cordero, 2015: 354-257). ${ }^{7}$

Pues bien, la Ley 20.600 no regula de un modo detallado qué debe entenderse por «procedimiento administrativo de invalidación». Frente a los vacíos de las normas que regulan procedimientos especiales, hay que entender que estos son completados por la Ley 19.880 (Vergara, 2005: 41). Así, a falta de una regulación de un procedimiento de invalidación en la Ley 20.600, se debe aplicar el artículo 53 de la Ley 19.880. En consecuencia, la resolución que resuelve un procedimiento de invalidación conforme con el citado artículo 53 debiese abrir la posibilidad de acudir ante el tribunal ambiental. De este modo, podemos decir que se verifica una supletoriedad de segundo grado, pues el artículo 17 núm. 8 solo regula la impugnación judicial de los actos que resuelven procedimientos de invalidación de carácter ambiental, pero nada dice sobre el ejercicio de la potestad de invalidación por parte de la autoridad ambiental.

A pesar de lo anterior, la teoría de la invalidación impropia nos dice que el artículo 17 núm. 8 es una norma completa, pues contiene un recurso administrativo implícito cuyo plazo de interposición es de treinta días. De este modo, tal norma no debe ser completada con la regla general de la Ley 19.880 sobre invalidación (artículo 53). Sin embargo, los fallos que sustentan la idea de invalidación impropia argumentan que el artículo 17 núm. 8 no es óbice para que la autoridad ambiental pueda ejercer el poder

7. Véase también, Corte Suprema, rol 29.714-2014, 20 de mayo de 2015, considerando octavo. 
del artículo 53 de la Ley 19.88o. Pero en caso de que la autoridad decida invalidar su propio acto, tal decisión será impugnable ante el tribunal ambiental respectivo, mientras que si decide no invalidar no habrá recurso alguno.

Con lo anterior, quedan a la vista dos incoherencias de la teoría de la invalidación impropia. Primero, a pesar de que se entiende que el artículo 17 núm. 8 de la Ley 20.600 no puede ser completado por el artículo 53 de la Ley 19.880 (pues ambas normas regulan supuestos distintos) sin mediar explicación, se entiende también que el artículo 17 núm. 8 se comporta como norma especial para efectos de determinar el tribunal competente que conocerá de la impugnación de la invalidación de un acto de carácter ambiental cuando es ejercida la potestad del artículo 53 de la Ley 19.880 . Así la incoherencia consiste en que se entiende que el artículo 17 núm. 8 no es norma especial porque no regula un supuesto de invalidación propiamente tal, sino que un recurso administrativo de legalidad, pero sí es especial para efectos de determinar el tribunal competente para conocer del conflicto que genera el ejercicio de la potestad de invalidación «propiamente tal» del artículo 53.

Segundo, si admitimos que el artículo 17 núm. 8 de la Ley 20.600 se comporta como norma especial para efectos de señalar el tribunal competente para impugnar el acto invalidatorio, ello implica admitir también que el supuesto regulado por el artículo 17 núm. 8 no es distinto del regulado por el artículo 53, porque de lo contrario no podrían relacionarse como norma especial y general. En este contexto, no es lógico denegar el acceso al tribunal ambiental a quien ve rechazada su solicitud de invalidación. Esto porque, si el artículo 17 núm. 8 es norma especial respecto del 53, se debiese preferir, por especialidad, la regla del artículo 17 núm. 8 que permite la impugnación de todo acto que resuelva un procedimiento de invalidación de un acto de carácter ambiental (ya sea que disponga la invalidación o la deniegue) y no la regla general que permite impugnar solo el acto que dispone la invalidación.

Considerando lo anterior, para dar coherencia a la teoría de la invalidación impropia, habría que afirmar lo siguiente. El artículo 17 núm. 8 de la Ley 20.600 es una norma especial y completa, que regula un recurso administrativo que no tiene relación con el artículo 53 de la Ley 19.880 . La Ley 20.600 no regula en absoluto la invalidación propiamente tal, por lo que se verifica una supletoriedad de primer grado. El artículo 53 de la Ley 19.880 debe recibir aplicación íntegra y no puede ser completado por el 17 núm. 8 de la Ley 20.60o, pues es una norma completa referida a una potestad distinta: la de conocer y resolver el recurso de invalidación impropio. Consecuencialmente, el acto que deniega la invalidación no es susceptible de recurso alguno y que el acto de invalidación dictado por una autoridad ambiental es impugnable ante los tribunales ordinarios de justicia en procedimiento «breve y sumario».

No obstante, este esfuerzo por darle coherencia a la teoría de la invalidación impropia tiene un serio inconveniente. Esta interpretación va en contra del espíritu de la Ley 20.600, que buscaba reconducir todos los conflictos de tipo ambiental hacia los 
tribunales ambientales especializados. De este modo, resulta que la única interpretación coherente de las normas citadas consiste en entender que el artículo 17 núm. 8 de la Ley 20.600 es una norma que debe ser suplida por el artículo 53 de la Ley 19.880. Por lo tanto, los actos que resuelvan un procedimiento de invalidación (ya sea que den lugar o denieguen la invalidación) son impugnables dentro del plazo de treinta días ante el tribunal ambiental respectivo y tal invalidación puede ser decretada hasta dos años después de la notificación del acto ambiental respectivo. Con esto, como se señaló, se sacrifica la seguridad jurídica. No obstante, más adelante se verá que existen otros mecanismos para paliar este problema distintos de la rígida regla de preclusión que promueve la teoría de la invalidación impropia.

\section{Acceso a la justicia}

La tercera objeción que es posible plantear a la tesis de la invalidación impropia tiene que ver con el debido proceso y el acceso a la justicia. Restringir el acceso a la jurisdicción ambiental a través de una regla de caducidad de treinta días no es algo que genere problemas a quienes participan en el procedimiento administrativo, ya sea como promotores o terceros, titulares de derechos o intereses; o para quienes participen través de los procedimientos de consulta previstos en la legislación.

Tal regla sí puede ser problemática para los terceros que no participaron en el procedimiento de evaluación ambiental. Esto se debe a que, pasados los treinta días previstos para la impugnación de un acto de carácter ambiental, la posibilidad de acceder a los tribunales ambientales queda entregada al arbitrio del Servicio de Evaluación Ambiental, pues si este decide no invalidar, no habría ulterior recurso.

Podría argumentarse que tal restricción se encuentra justificada, teniendo en cuenta los procedimientos de participación que contempla nuestra legislación. Sin embargo, los mecanismos de consulta ciudadana o indígena no están destinados a hacer precluir la posibilidad de iniciar procedimientos de revisión o para interponer acciones judiciales. Más bien, son herramientas que buscan dar transparencia a los procesos y permitir la participación generalizada de la población en la toma de decisiones (Pinilla, 2014: 294; Riestra, 2019: 48). Por lo demás, tales mecanismos no proceden siempre (Bordalí y Hunter, 2020: 189-190).

Por otro lado, como ya se ha dicho, en los últimos años la Corte Suprema ha decidido no ejercer sus amplios poderes para resolver recursos de protección en materia ambiental de acuerdo con el artículo 20 de la Constitución, pues considera que la existencia de una jurisdicción especializada obliga a los particulares utilizar los mecanismos de la Ley 20.600 (Riestra, 2019: 37-38), y algo similar ha ocurrido con la acción de nulidad de derecho público: existiendo acciones especiales, estas deben ser preferidas frente a la general establecida en la Constitución. Más allá de si esta postura del máximo tribunal es correcta o no, es posible vaticinar que, si se deniega de 
modo sistemático el acceso a la justicia a los terceros ajenos al procedimiento de evaluación ambiental, es probable que vuelvan a cobrar fuerza las acciones contenciosoadministrativas generales de nulidad de derecho público y el recurso de protección.

De hecho, el ministro Muñoz ha prevenido que el tribunal debiese conocer de los recursos de protección independiente de si existen procedimientos de reclamación especiales, si se cumplen los supuestos previstos en el artículo 20 de la Constitución. ${ }^{8}$ Siguiendo esta línea de razonamiento, este ministro ha sostenido en un artículo de carácter doctrinal que el acceso a la justicia en materia ambiental implica la existencia de una acción judicial accesible a quienes se vean afectados por las decisiones ambientales (Muñoz, 2014: 25-26). ${ }^{9}$ Si lo anterior no es proveído por la legislación especial, pienso que el ministro Muñoz tiene razón: nada impide que los tribunales ordinarios empiecen a conocer de estos asuntos a través de las acciones contenciosoadministrativas generales. La falta de medios adecuados para proteger un interés podría justificar en un caso particular el control a través de un recurso de protección (Fermandois y Chubretovic, 2015: 71-74, 84).

De este modo, la tesis de la invalidación impropia puede terminar truncando uno de los propósitos centrales de la Ley 20.600: que los conflictos en materia ambiental no se canalicen a través de la jurisdicción especializada creada al efecto. Por esto, atendida la especialización ambiental y económica de los tribunales creados por la Ley 20.600 (Bermúdez Soto, 2014: 346), resulta razonable abandonar la tesis de la invalidación impropia y optar por una interpretación que integre los artículos 17 núm. 8 de la Ley 20.600 y 53 de la Ley 19.880, y permita canalizar de modo generalizado los conflictos a través de los tribunales ambientales.

\section{Invalidación impropia: ¿un equilibrio de los intereses en juego?}

Podría argumentarse que la teoría de la invalidación impropia provee una solución equitativa frente a los vacíos e inconsistencias de la regulación contenida en la Ley 20.60o. De acuerdo con este planteamiento, se otorga una mayor estabilidad a las resoluciones de calificación ambiental a través del plazo de impugnación de treinta días. Transcurrido este término, los terceros eventualmente afectados todavía tienen una oportunidad de que el acto sea revisado, aunque la vía judicial quedará abierta solo en el caso de que el Servicio de Evaluación Ambiental disponga la invalidación. Pero en la práctica, la teoría de la invalidación impropia incentiva que la autoridad ambiental aloje el costo que supone invalidar una resolución de calificación ambiental en el interés público, en el titular del proyecto o en los terceros afectados, descargando así de responsabilidad al órgano administrativo.

8. Corte Suprema, rol 35.244-2016, 5 de septiembre de 2016.

9. Véase también, Corte Suprema, rol 6121-2017, 6 de junio de 2017. 
Lo anterior se puede mostrar teniendo en cuenta los distintos intereses tras el control de legalidad de un acto administrativo. Cuando un órgano de la Administración actúa fuera de su competencia, los costos del error pueden quedar alojados en distintos lugares: primero, puede ser transferido al interés público o a los terceros afectados, como cuando se mantienen en el tiempo los efectos de actos ilegales por existir las llamadas «situaciones jurídicas consolidadas»; segundo, puede ser transferido al particular beneficiario de la decisión ilegal, cuando esta es invalidada con efecto retroactivo; $y$, tercero, puede ser transferida al órgano administrativo que dictó el acto ilegal, si se considera que la invalidación del acto pone al órgano administrativo en la situación de tener que indemnizar los perjuicios causados por el acto ilegal (Craig, 2016: 701-702).

Lo anterior tiene importantes consecuencias respecto de la invalidación ambiental. Antes del transcurso de los treinta días para interponer el reclamo de legalidad implícito en el artículo 17 núm. 8, no sería posible entender que el acto está firme (Valdivia, 2018: 210-211), ya que se trataría de un recurso administrativo análogo al de reposición previsto en la Ley 19.880. Por esto, la invalidación del acto solo perjudicaría al particular que obtuvo la decisión favorable. Pero después de los treinta días, la teoría de la invalidación impropia brinda mayor estabilidad a las resoluciones de calificación ambiental, pues solo se permite que el mismo Servicio de Evaluación Ambiental inicie un procedimiento de invalidación, ya sea de oficio o a petición de parte. En este caso, frente a la existencia de un posible vicio, la autoridad tiene fuertes incentivos para rechazar la solicitud de invalidar una resolución de calificación ambiental en ejecución. Esto se debe a que, aplicando la teoría de la invalidación impropia, el órgano sabe que contra la resolución que deniega la invalidación no procede recurso alguno y que, si invalida su propia resolución de calificación ambiental, podría quedar al descubierto la existencia de una falta de servicio y ver comprometida su responsabilidad patrimonial por los daños causados a quien fuera ilegalmente autorizado a realizar una actividad (Letelier, 2014: 627-629).

Frente a lo anterior, podría argumentarse que la teoría de la invalidación impropia no favorece el interés de la propia autoridad, pues la legislación mandata a los organismos administrativos a actuar siempre en servicio de las personas promoviendo el bien común, tal como lo establece el artículo 1 de la Constitución y el artículo 3 de la Ley 18.575. Por lo demás, se invalide o no una resolución de calificación ambiental, podría quedar comprometida la responsabilidad de la autoridad por haber realizado una evaluación ambiental deficiente (Femenías, 2017: 241-256).

Sin embargo, estos argumentos se pueden descartar. Para esto es preciso distinguir entre el «interés público» que todo órgano administrativo debe perseguir con el «interés fiscal». Interés fiscal es la necesidad de proteger el patrimonio y los bienes de un órgano administrativo; mientras que interés público consiste en la necesidad pública que cada organismo debe satisfacer por encargo de legislador (Phillips, 2020: 
289). En este contexto, el Servicio de Evaluación Ambiental podría tender a denegar la invalidación de una resolución de calificación ambiental como una forma de protegerse frente a eventuales pretensiones indemnizatorias, sobre todo sabiendo que contra tal decisión no procede recurso alguno. De este modo, el eventual comportamiento ilegal del órgano (requisito fundamental de la falta de servicio) quedaría cubierto bajo el manto de la presunción de legalidad del acto administrativo.

De este modo, transcurrido el plazo de los treinta días, el costo del error tenderá a quedar alojado en el interés público o en los terceros afectados. Y, como ya se explicó en la sección anterior, ello podría revitalizar el uso de acciones contencioso-administrativas generales en contra de una resolución de calificación ambiental, pues como forma de proteger la tutela judicial efectiva los tribunales ordinarios podrían reaccionar protegiendo a quienes se vean impedidos de acceder a los tribunales ambientales para llevar adelante sus pretensiones.

Por esto, lo lógico sería abandonar la idea de que el artículo 17 núm. 8 contiene un recurso administrativo de invalidación impropia, y simplemente entender que tal norma contiene un reclamo de legalidad para impugnar la decisión fruto de un procedimiento de invalidación, sea que se ordene la invalidación o se deniegue. Así, la Ley 20.600 es vista como una norma que supone la existencia de la potestad de invalidación del artículo 53 de la Ley 19.880 y aplica como norma de carácter especial para determinar el plazo para impugnar la decisión que resuelve un procedimiento invalidatorio y el tribunal competente. Lo anterior concuerda con el texto de la norma y con la historia de la Ley 20.600 , donde no se observan distinciones entre la invalidación propiamente tal y la «invalidación-recurso», sino que simplemente se refiere a que antes de reclamar la legalidad de un acto de carácter ambiental se requiere iniciar un procedimiento de invalidación ante el Servicio de Evaluación Ambiental (BCN, 2012: 264-278).

\section{Protección de la certeza jurídica: equilibrando estabilidad y revisión}

Lo afirmado conduce a reconocer que el Servicio de Evaluación Ambiental puede invalidar dentro de un plazo de dos años un acto de carácter ambiental y que, eventualmente, tal decisión puede ser impugnada ante los tribunales ambientales en el plazo de treinta días desde su notificación. Con esto, una resolución de calificación ambiental podría ser impugnada mucho tiempo después de haber quedado administrativamente firme, de modo que se podría lesionar la seguridad jurídica de quien inició la ejecución de un proyecto sobre la base de dicha autorización (Carrasco y Benítez, 2017: 121). En este contexto, cobran importancia los procedimientos de participación como un modo de resolver de modo anticipado los problemas que pueda traer una decisión en materia ambiental (Mirosevic, 2011: 285-287; Carrasco y Benítez, 2017: 124-126). Con todo, puestos en la situación de que existan vicios en una resolución de 
calificación ambiental, hay que preguntarse qué mecanismos se podrían considerar para proteger la estabilidad de estos instrumentos y, por tanto, la seguridad jurídica de los desarrolladores de proyectos.

Al tomar decisiones en materia ambiental hay que tener en cuenta dos factores. Un primer factor es la seguridad jurídica y la libertad económica. Es preciso considerar que el sistema de evaluación ambiental «ejerce su más poderosa influencia» en quienes desarrollan proyectos, pues viene a «regular, asegurar y a la vez, limitar la libertad en materia económica» (Bermúdez Soto, 2014: 263). Dicho de otro modo, las autorizaciones ambientales influyen en cómo los particulares ejercen su libertad económica: ellos realizan gastos e inversiones sobre la base de lo dispuesto en ellas. En consecuencia, la invalidación de una resolución de calificación ambiental podría ser lesiva de la garantía constitucional del artículo 19 núm. 21 en el sentido de que como resultado de una errónea evaluación ambiental un particular sufra perjuicios inmerecidos (Arancibia, 2016: 186-187).

Como segundo factor hay que considerar los principios preventivo y precautorio que informan el derecho medioambiental. Al respecto, es relevante que la autoridad ambiental actúe eliminando impactos ambientales ya comprobados y disminuyendo los riesgos que puede generar una actividad, todo de un modo racional. ${ }^{10}$ Estos principios obligan a aceptar una cierta inestabilidad jurídica en el derecho medioambiental, con las inseguridades que ello conlleva (Carrasco y Herrera, 2014: 665).

Considerando lo anterior, aunque la mayor parte de la doctrina entiende que la declaración de nulidad de una autorización ambiental tiene un necesario efecto retroactivo, la invalidación con efecto ex tunc de una autorización ambiental, como se explicó, puede tener efectos contrarios a la libertad económica protegida por la Constitución. En este contexto, se puede entender la jurisprudencia de la Contraloría General de la República que protege situaciones jurídicas consolidadas frente al ejercicio de la potestad de invalidación de los órganos administrativos (Millar, 2012; Boettiger, 2009; Bermúdez Soto, 2005). ${ }^{11}$

De este modo, mitigar los efectos retroactivos de la invalidación de una resolución de calificación ambiental puede ser mirado como un imperativo de cara a la protección que debe recibir la libertad en materia económica (Phillips, 2020: 206-210). Con todo, en materia ambiental, el planteamiento de la Contraloría General todavía deja importantes problemas por resolver (Riestra, 2019: 46-47). En efecto, proteger solo la libertad económica de los titulares de los proyectos frente a la invalidación de una resolución de calificación ambiental en ejecución iría en contra de los principios

10. Corte Suprema, rol 2463-2012, 11 de mayo de 2012, considerando sexto; Corte Suprema, rol 21382012, 27 de julio de 2012, considerando cuarto.

11. Ver también dictámenes de la Contraloría General de la República 51775 de 2013, 83849 de 2014 y 85976 de 2015, entre otros. 
preventivo y precautorio encaminados a asegurar el derecho a vivir en un medio ambiente libre de contaminación.

En este contexto, hay que entender que no es posible proteger rígidamente la posición jurídica del beneficiario de una resolución de calificación ambiental viciada. Al respecto, frente a la existencia de estas situaciones jurídicas consolidadas he propuesto aplicar una regla flexible de protección que contemple distintas medidas teniendo en cuenta el interés público tras la norma quebrantada y el interés de los particulares afectados (Phillips, 2020: 261-270). Por esto, a continuación, se concretará la propuesta mencionada a la materia medioambiental, para entender cómo es posible conjugar la libertad económica y la protección ambiental frente a la invalidación de una resolución de calificación ambiental. Esto se hará mostrando que la autoridad administrativa no necesariamente debe invalidar con efecto ex tunc una resolución de calificación ambiental cuando existen vicios, sino que puede tomar tres cursos de acción distintos: la convalidación de la resolución de calificación ambiental, la adaptación de la resolución de calificación ambiental o la indemnización de perjuicios.

\section{Convalidación del vicio}

Una primera actitud que se podría asumir es la de convalidar una resolución de calificación ambiental viciada. Pienso que lo anterior sería una solución aceptable en aquellas situaciones en que los impactos ambientales que dan lugar a la declaración de nulidad son de menor entidad. De esta manera, se trata de una situación en que los vicios que justifican la anulación no son de mayor preponderancia de cara a la precaución ambiental general o frente al derecho a vivir en un medio ambiente libre de contaminación del tercero afectado. En definitiva, se trata de casos en que los vicios tras la pretensión anulatoria protegen un interés que, en realidad, puede convivir con la mantención en el tiempo de la resolución de calificación ambiental cuestionada, más allá del quebrantamiento a la legalidad formal.

Lo anterior merece una explicación. Si entendemos que el objetivo del Sistema de Evaluación de Impacto Ambiental es determinar en qué condiciones una actividad de las numeradas en el artículo 1o de la Ley 19.300 que causa impacto ambiental puede ser autorizada, conjugando la libertad económica con la protección medioambiental, luego es posible imaginar que no cualquier vicio del procedimiento o sustantivo en la resolución de calificación ambiental debiese conducir a su anulación ex tunc.

Pueden existir impactos ambientales no analizados en el procedimiento de evaluación que, por su insignificancia, no justifiquen anular una autorización. Esto, aunque desde una concepción estricta de la legalidad se trate de impactos que debieron ser evaluados. En este caso, la Administración ambiental podría ejercer la potestad de convalidación prevista en el inciso final artículo 13 de la Ley 19.880. Al respecto, Bermúdez entiende de modo amplio esta potestad de convalidación, la que puede 
ser ejercida respecto de vicios formales y sustantivos. Señala el mencionado autor: «Dado que la LBPA [Ley de Bases de Procedimiento Administrativo] en el inciso segundo del artículo 13 ya señaló los requisitos para que el acto administrativo sea ilegítimo por vicios de procedimiento, y que el inciso tercero discurre sobre vicios del acto administrativo y no del procedimiento administrativo, es plausible una interpretación extensiva de la norma, esto es, la que aplicando el principio de conservación del acto administrativo, permite la convalidación de otros vicios no formales o procedimentales» (Bermúdez Soto, 2010: 110; cf. Bermúdez Soto, 2011: 135-136). Para esto la Administración tiene que demostrar que el interés esgrimido por quien solicita la invalidación no es incompatible con la mantención en el tiempo de la autorización viciada, de modo que se pueda concluir que el tercero no tiene un interés realmente afectado por la decisión de convalidación.

De modo analógico, se puede considerar lo que ha dicho parte de la doctrina y la jurisprudencia de la Contraloría General de la República sobre el denominado principio de oportunidad en materia de fiscalización y sanción ambiental. En materia de infracciones ambientales es posible observar una tensión entre el cumplimiento de la legalidad y la oportunidad o conveniencia de iniciar un procedimiento sancionador. Algunos sostienen que, frente a la existencia de una infracción a lo dispuesto en algún instrumento ambiental, es deber del órgano iniciar el respectivo procedimiento sancionador (Bermúdez Soto, 2013: 439); mientras que otros, en forma más reciente, han reconocido un margen de discrecionalidad para que la Superintendencia del Medio Ambiente decida iniciar o no determinados procedimientos, considerando la entidad de la supuesta infracción y la economía en el uso de sus propios recursos (Hunter, 2020: 103-118; Soto, 2016: 208-215).

Algo similar podría sostener respecto de los eventuales impactos no previstos objeto de este trabajo. Para dar lugar a una invalidación, deben estar revestidos de cierta entidad. De lo contrario se podrá ejercer la potestad de convalidación de la Ley 19.880. Para ejemplificar lo anterior, se pueden analizar los hechos de la causa Álvaro Castro y otros con Servicio de Evaluación Ambiental. ${ }^{12}$ El caso trató de un proyecto de infraestructura complementaria para mejorar el abastecimiento de agua de una mina, que fue aprobado a través de un estudio de impacto ambiental luego de un amplio proceso de participación ciudadana. Pues bien, los pobladores de la comunidad de Caimanes solicitaron la invalidación de la resolución de calificación ambiental argumentando, inter alia, que en su localidad no se realizaron actividades para asegurar su participación en el procedimiento. Esto a diferencia de otras localidades como Los Vilos, Salamanca e Illapel. En este contexto, señalaron que su pueblo era el más cercano al tranque de relave contemplado en el proyecto, lo que afectaría su derecho a vivir en un medio ambiente libre de contaminación.

12. Primer Tribunal Ambiental, rol R-33-2019, 5 de octubre de 2020. 
La solicitud fue rechazada en virtud de la teoría de la invalidación impropia, ya que el plazo de treinta días había expirado. Sin embargo, en este caso, es posible anotar que los reclamantes no señalan de modo claro de qué modo se vería afectado su derecho a vivir en un medio ambiente libre de contaminación, más allá de no haber podido hacerse parte en el procedimiento. En este contexto, se puede considerar que el vicio que existía en este procedimiento no era esencial y, por tanto, no ameritaba declarar la nulidad del procedimiento. ${ }^{13}$

Con esto, si no se demuestra la existencia de impactos ambientales que hagan incompatible la mantención en el tiempo de una resolución de calificación ambiental con el derecho a vivir en un medio ambiente libre de contaminación, no se debiese dar lugar a la invalidación y la autoridad debiese convalidar el vicio ejerciendo su potestad del artículo 13 de la Ley 19.880. Para evaluar lo anterior puede ser útil el criterio desarrollado por la Corte Suprema de que en el sistema de evaluación ambiental «no se busca que la actividad de los particulares quede en estándares de riesgo cero, sino que, como primera medida, los riesgos advertidos por estudios fundados sean considerados y se adopten respecto de ellos las medidas pertinentes, que no se les ignore». ${ }^{14}$

Se podría argumentar que, con lo que estoy planteando, se incumple con la regla de que todos los impactos deben ser evaluados. No obstante, si se prevé que el impacto no evaluado no será de mayor magnitud, pienso que la autoridad debiese convalidar el vicio teniendo en cuenta que su función no es reducir los riegos a cero, sino gestionar los posibles impactos compatibilizando de un modo razonable la libertad económica con la protección ambiental. Por ejemplo, en una oportunidad el Tercer Tribunal Ambiental consideró que el bajo impacto sobre el bosque nativo de un sitio prioritario (del o,17\%) configuraba un vicio no esencial en la evaluación ambiental. ${ }^{15}$

\section{Adaptación de la resolución de calificación ambiental}

Fuera del caso descrito, durante el amplio plazo para solicitar la invalidación de una resolución de calificación ambiental es posible que se identifiquen vicios que hagan incompatible la ejecución de un proyecto con el interés público de proteger el medio ambiente y asegurar la garantía constitucional de vivir en un medio ambiente libre de

13. Primer Tribunal Ambiental, rol R-33-2019, 5 de octubre de 2020, considerando $43 .{ }^{\circ}$ de la prevención del ministro Marcelo Hernández.

14. Corte Suprema, rol 97.792-2016, 6 de noviembre de 2017, considerando 41. ${ }^{\circ}$; Corte Suprema, rol 7876-2013, 18 de diciembre de 2013, considerando cuarto.

15. Primer Tribunal Ambiental, rol R-7-2019, 28 de enero de 2020, considerandos $67 .^{\circ}$ y $68 .^{\circ}$. Sin perjuicio de lo anterior, en este caso particular, de todos modos, el tribunal decidió invalidar por existir otros posibles impactos que era necesario considerar, que sí eran esenciales (cfr. Primer Tribunal Ambiental, rol R-7-2019, 28 de enero de 2020, considerando $75 .^{\circ}$ ). 
contaminación. Esto ocurriría cuando el impacto no evaluado o el vicio invocado sí tenga la debida preponderancia.

A pesar de lo anterior, tampoco en este caso necesariamente estaría justificada una invalidación ex tunc de una resolución de calificación ambiental sin más. Lo anterior podría derivar en una lesión injustificada contra la libertad económica en cuanto que ella fue dirigida o influenciada por la autoridad que autorizó el proyecto. Por ejemplo, puede ocurrir que solo parte del proyecto genere el impacto no evaluado, que el impacto no evaluado se pueda producir solo en un largo plazo o que una modificación parcial del proyecto sea suficiente para mitigar ese impacto. En estas situaciones la Administración tiene las herramientas jurídicas para adaptar la resolución de calificación ambiental al impacto no evaluado y así evitar recurrir a la invalidación retroactiva de la autorización.

¿Cómo hacer esto? Una posibilidad es que el órgano invalide solo parcialmente una resolución de calificación ambiental, tal como expresamente lo permite el artículo 53 de la Ley 19.880. Otra posibilidad es que, tratándose de riesgos que amenazan verificarse en el largo plazo, la autoridad disponga una invalidación con efecto diferido. Esto ha sido admitido como un posible mecanismo para proteger confianzas legítimas generadas por un acto ilegal (Letelier, 2014: 627-628), y podría ser una medida útil mientras se realiza una nueva evaluación del proyecto. Por otro lado, aunque existan vicios esenciales, nada obliga a que el proyecto vuelva al inicio o sea prohibido, sino que se puede disponer una invalidación parcial para evaluar aspectos determinados, como lo ha resuelto el Primer Tribunal Ambiental. ${ }^{16}$

Por último, si fuera necesaria una reformulación del proyecto, el Servicio de Evaluación Ambiental podría invalidar una resolución de calificación ambiental con efecto ex tunc y luego dictar una nueva con efecto retroactivo, aplicando excepción a la irretroactividad del acto administrativo prevista en el artículo 52 de la Ley 19.88o. Esto sería posible en la medida en que la nueva resolución de calificación ambiental se haga cargo de todos los impactos ambientales relevantes, de manera que compatibilice el derecho a vivir en un medio ambiente libre de contaminación de los terceros afectados con la actividad que el titular del proyecto se propone realizar, de manera que sus derechos no se vean afectados negativamente. De este modo, una autorización puede ser «adaptada» para que considere el impacto no evaluado en la decisión original y así se evita una lesión a los «derechos de terceros» que impide la retroactividad favorable.

Para ejemplificar lo anterior se puede considerar la causa caratulada Junta de Vecinos núm. 11 Maitencillo Norte con Servicio de Evaluación Ambiental. ${ }^{17}$ En esta oportunidad, se interpuso una reclamación en virtud del artículo 17 núm. 8 de la Ley 20.600

16. Primer Tribunal Ambiental, rol R-7-2019, 28 de enero de 2020, considerandos $75 .{ }^{\circ} \mathrm{al} 79 .{ }^{\circ}$.

17. Corte Suprema, rol 16.263-2015, 16 de agosto de 2016. 
en contra de la decisión de no invalidar el acto que aprobó la declaración de impacto ambiental de un proyecto inmobiliario. El reclamante alegó que la resolución de calificación ambiental estaba viciada por no haberse considerado adecuadamente la factibilidad sanitaria del proyecto, al no existir suficiente disponibilidad de agua para una nueva urbanización, entre otros problemas.

La Corte Suprema decidió aplicar la teoría de la invalidación impropia y, en definitiva, rechazó el reclamo porque la invalidación-recurso fue solicitada fuera del plazo de treinta días desde la notificación de la decisión impugnada. Con todo, en lugar de haber aplicado la regla rígida de la teoría de la invalidación impropia, el Servicio de Evaluación Ambiental debiese haber evaluado el fondo del asunto. Al respecto, de existir el problema hídrico denunciado se podría haber invalidado la resolución de calificación ambiental dictada y haber solicitado la presentación de una nueva declaración de impacto ambiental de acuerdo con la realidad hídrica de la zona.

\section{Indemnización de perjuicios por gastos e inversiones}

Por último, pueden existir situaciones en que la mantención en el tiempo de una resolución de calificación ambiental viciada sea en forma absoluta incompatible con la protección ambiental y no sea posible adaptar tal acto para compatibilizar el interés del particular con la protección ambiental. En tal situación, en la medida que el particular haya obrado con la debida diligencia (Letelier, 2014: 628-629; Phillips, 2020: 253-259), tal como puede atribuirse un determinado daño ambiental a la Administración por una deficiente evaluación ambiental (Femenías, 2017: 252-253), también una autorización antijurídica y su posterior invalidación pueden causar daños indemnizables a un particular atribuibles a una falta de servicio. En este caso, no sería la autoridad responsable solo por los eventuales daños ambientales, sino también de los perjuicios generados en el particular que haya efectuado gastos o inversiones como consecuencia de una errónea autorización.

En este punto hay que preguntarse cuándo se puede producir un perjuicio indemnizable. Lo que justifica una indemnización en este caso es la inutilización de gastos o inversiones hechas teniendo a la vista la autorización anulada. De este modo, la sola invalidación no necesariamente produce perjuicios indemnizables. Por ejemplo, podría ocurrir que se invalide una resolución de calificación ambiental otorgada en virtud de una declaración de impacto ambiental y se ordene que el proyecto se tramite a través de un estudio de impacto ambiental. ${ }^{18}$ En ese caso, es posible que el proyecto termine siendo autorizado de todas formas, aunque luego de una evaluación más exigente.

18. Por ejemplo, Corte Suprema, rol 3141-2012, 15 de junio de 2012; Corte Suprema, rol 1960-2012, 28 de agosto de 2012,. 
Como consecuencia de lo dicho, independiente de la decisión que se adopte, es necesario considerar qué inversiones fueron efectivamente inutilizadas por la decisión de invalidar la resolución de calificación ambiental y qué costos adicionales generó la paralización, momentánea o definitiva, del proyecto. De este modo, es necesario hacer un análisis cuidadoso al determinar los perjuicios indemnizables. Por otro lado, también es necesario apreciar quién fue el responsable del error que desencadenó la declaración de nulidad. En particular, hay que analizar si este se debió a defectos en la información que el particular entregó o debía entregar, o si, al contrario, se debió a una falta de fiscalización de la autoridad ambiental.

\section{Conclusiones}

En este artículo se ha analizado la tensión entre precaución y estabilidad en materia medioambiental respecto del problema que supone la invalidación de una resolución de calificación ambiental, cuando esto es solicitado por un tercero. Al respecto, se analizaron las dos teorías existentes sobre el plazo que existe para que el Servicio de Evaluación Ambiental invalide una resolución de calificación ambiental. Estas fueron sometidas a críticas y se propuso una regla flexible para determinar cómo se debiesen concretar los efectos en el tiempo de la invalidación de una resolución de calificación ambiental. De lo expuesto se pueden extraer las siguientes conclusiones:

Las distintas interpretaciones o teorías sobre el artículo 17 núm. 8 de la Ley 20.600 presentan dificultades que es necesario tener presentes. Por un lado, el planteamiento que propone que toda resolución que termina un procedimiento de invalidación, dictada dentro del plazo de dos años desde la notificación del acto, es impugnable ante los tribunales ambientales parece privilegiar en forma excesiva la precaución ambiental en desmedro de la seguridad jurídica. Por otro lado, la teoría de la invalidación impropia parece privilegiar en forma excesiva la seguridad jurídica, limitando en gran medida las posibilidades de obtener una revisión juridicial efectiva de la legalidad de una resolución de calificación ambiental.

La teoría de la invalidación impropia puede ser descartada por tres razones. Primero, porque no se aviene con el principio de legalidad ni con el texto del artículo 17 núm. 8 de la Ley 20.60o. En efecto, la mencionada postura no explica de modo suficiente cómo este reclamo administrativo de legalidad implícito sería compatible con el artículo 7 de la Constitución, ni tampoco cómo un procedimiento de invalidación iniciado conforme con el artículo 53 de la Ley 19.880 no sería una resolución que resuelve «un procedimiento administrativo de invalidación» de los que habla el texto del artículo 17 núm. 8. Segundo, la teoría de la invalidación impropia utilizada de un modo incoherente las técnicas de la supletoriedad y de la especialidad. Por un lado, se considera que el artículo 17 núm. 8 es una norma especial respecto del 53 para efectos de la impugnación judicial del acto que dispone la invalidación de un 
acto de carácter ambiental, pero también se considera que el artículo 17 núm. 8 es una norma completa que regula un recurso administrativo especial e implícito, lo que no tiene consistencia teórica. Tercero, la teoría de la invalidación impropia limita en gran medida el acceso a la justicia, ya que los terceros a quienes les resulta imposible impugnar una resolución de calificación ambiental en el breve plazo de treinta días solo tienen la posibilidad de acudir ante la autoridad administrativa para que revise su decisión y ante la negativa de invalidar no tienen otro recurso. Por lo demás, esto podría revitalizar acciones contencioso-administrativas generales, como el recurso de protección y la nulidad de derecho público, desviando estos conflictos de la jurisdicción ambiental creada al efecto, lo que tampoco es deseable.

Si se consideran los intereses el juego tras la invalidación de una resolución de calificación ambiental se puede concluir lo siguiente. La teoría de la invalidación impropia tiende al proteger en mayor medida el interés del titular del proyecto y el interés fiscal del órgano administrativo, en el sentido de no ser objeto de acciones de responsabilidad por una deficiente evaluación ambiental. De este modo, tiende a alojar el costo de una deficiente evaluación ambiental en el interés público o en los terceros afectados una vez que se vence el plazo de treinta días. Por su parte, la interpretación que posibilita invalidar una resolución de calificación ambiental dentro de los dos años del artículo 53 de la Ley 19.880 tiende a alojar el costo de la deficiente evaluación ambiental en el titular del proyecto. De este modo, aunque la teoría de la invalidación impropia pueda ser descartada por otras razones, es necesario considerar cómo lograr un adecuado equilibro entre seguridad y precaución en circunstancias que una resolución de calificación ambiental puede ser invalidada administrativamente, y tal decisión recurrida ante el tribunal ambiental, dentro del plazo de dos años desde su notificación.

Para abordar los problemas de seguridad generados por el plazo de dos años para invalidar una autorización ambiental es necesario considerar el rol que tienen en este punto el principio de protección de la confianza y la jurisprudencia de la Contraloría General de la República sobre situaciones jurídicas consolidadas. Dado que las autorizaciones ambientales influyen en la toma de decisiones económicas de los particulares, parece excesivo que todo vicio contenido en una resolución de calificación ambiental dé lugar a la invalidación retroactiva o ex tunc. Al respecto, para proteger la garantía de libertad económica, es necesario mitigar los efectos retroactivos de la invalidación, pero de un modo que sea compatible con el principio precautorio ambiental. Por esto, se propone las siguientes medidas: la convalidación de la resolución de calificación ambiental, cuando el vicio no suponga un riesgo mayor para el medio ambiente; la adaptación cuando la protección del medio ambiente demande invalidar la resolución de calificación ambiental pero la realización del proyecto pueda ajustarse a los impactos ambientales no evaluados que generaron el vicio, o la indem- 
nización de perjuicios cuando la invalidación inutilice inversiones efectuadas por el particular o genere costos adicionales derivados de la paralización momentánea o definitiva del proyecto.

\section{Referencias}

Arancibia, Jaime (2016). «Los puntos de prueba en los litigios de impugnación de actos administrativos». En Jaime Arancibia Mattar y Alejandro Romero Seguel (coords.), La prueba en la litigación pública (pp. 161-191). Santiago: Librotecnia.

Ávila, Humberto (2016). Certainty in Law. Cham: Springer.

BArros, Alberto y José Miguel Valdivia (2019). «Sobre el reclamo contra la resolución que interviene en un procedimiento de invalidación en materia ambiental». En Juan Carlos Ferrada Bórquez, Andrés Bordalí Salamanca y Magdalena Prieto Pradenas (coords.), La justicia ambiental ante la jurisprudencia. Actos de las II Jornadas de Justicia Ambiental (pp. 131-175). Santiago: Der.

BCN, Biblioteca del Congreso Nacional (2012). Historia de la Ley 20.60o. Disponible en https://bit.ly/35TFObs.

Bermúdez Soto, Jorge (2005). «El principio de confianza legítima en la actuación de la Administración como límite a la potestad invalidatoria». Revista de Derecho (Universidad Austral de Chile), 18 (2): 83-105. DOI: 10.4067/ So718-09502005000200004.

-. (2010). «Estado actual del control de legalidad de los actos administrativos: ¿qué queda de la nulidad de derecho público?». Revista de Derecho (Universidad Austral de Chile), 23 (1): 103-123. Disponible en https://bit.ly/3jl7UUQ.

-. (2011). Derecho Administrativo General. 2. ${ }^{a}$ edición. Santiago: Legal Publishing Chile.

-. (2013). «Fundamento y límites de la potestad sancionadora administrativa en materia ambiental». Revista de Derecho (Pontificia Universidad Católica de Valparaíso), 40: 421-447. DOI: 10.4067/So718-68512013000100013.

-. (2014). Fundamentos de Derecho Ambiental. 2. ${ }^{\text {a }}$ edición. Valparaíso: Ediciones Universitarias de Valparaíso.

Boettiger, Camila (2009). «El principio de la buena fe en la jurisprudencia de la Contraloría General de la República en materia urbanística». Revista de Actualidad Jurídica, 19 (1): 309-326.

Bordalí, Andrés e Iván Hunter (2020). Contencioso administrativo ambiental. 2. ${ }^{\text {a }}$ edición. Santiago: Librotecnia.

Bordalí, Andrés (2019). «El acceso a los tribunales ambientales». En Juan Carlos Ferrada Bórquez, Andrés Bordalí Salamanca y Magdalena Prieto Pradenas (coords.), La justicia ambiental ante la jurisprudencia. Actos de las II Jornadas de Justicia Ambiental (pp. 3-31). Santiago: Ediciones Der. 
CArrasco, Edesio (2018). Sistema de evaluación de impacto ambiental. Análisis y resolución de casos prácticos. Santiago: Ediciones Der.

CARRASCO, Edesio y Javier Herrera (2014). «La interpretación de la resolución de calificación ambiental». Revista Chilena de Derecho, 41 (2): 635-671. Disponible en https://bit.ly/3gXyMsE.

CARrasco, Edesio y Rodrigo Benítez (2017). «Criterios para determinar la compatibilidad entre la potestad invalidatoria y los recursos administrativos y judiciales de acuerdo a lo dispuesto al inciso final del artículo 17 núm. 8 de la Ley 20.600». Revista de Derecho Ambiental, 5 (8): 102-129. DOI: 10.5354/0719-4633.2017.47913.

Craig, Paul (2016). Administrative Law. 8. a edición. Londres: Sweet \& Maxwell.

Cordero, Luis (2013). «Los dilemas tras los vicios de la resolución de calificación ambiental. ¿Cómo dimensionar sus efectos?». En Juan Carlos Ferrada Bórquez (coord.), La nulidad de los actos administrativos en el derecho chileno. IX Jornadas de Derecho Administrativo (pp. 513-535). Santiago: Legal Publishing Chile.

-. (2015). Lecciones de Derecho Administrativo. 2. ${ }^{a}$ edición. Santiago: Legal Publishing Chile.

FEMENíAs, Jorge (2017). «La culpabilidad en la responsabilidad por daño ambiental y su relación con el Sistema de Evaluación de Impacto Ambiental». Revista de Derecho (Pontificia Universidad Católica de Valparaíso), 48: 233-259. DOI: 10.4067/ So718-68512017000100233.

Fermandois, Arturo y Teresa Chubretovic (2016). «El recurso de protección en asuntos ambientales: criterios para su procedencia posinstitucionalidad ambiental (2010-2015)». Revista Chilena de Derecho, 43 (1): 61-90. Disponible en https:// bit.ly/3A1qDuG.

HunTeR, Iván (2020). «Legalidad y oportunidad en el ejercicio de la potestad sancionadora en material ambiental». Revista de Derecho (Pontificia Universidad Católica de Valparaíso), 54: 95-125. DOI: 10.4067/So718-68512020005000105.

Letelier, Raúl (2014). «Contra la confianza legítima como límite a la invalidación de actos administrativos». Revista Chilena de Derecho, 41 (2): 609-634. DOI: 10.4067/ So718-34372014000200009.

Millar, Javier (2012). «El principio de protección de la confianza legítima en la jurisprudencia de la Contraloría General de la República: Una revisión a la luz del Estado de Derecho». En La Contraloría General de la República: 85 años de vida institucional (1927-2012) (pp. 417-429). Santiago: Contraloría General de la República.

Mirosevic, Camilo (2011). «La participación ciudadana en el procedimiento de evaluación de impacto ambiental y las reformas introducidas por la Ley 20.417». Revista de Derecho (Pontificia Universidad Católica de Valparaíso), 36: 281-323. Disponible en https://bit.ly/2TbHSJa.

MuÑoz, Sergio (2014). «El acceso a la justicia ambiental». Justicia Ambiental, 6: 17-38. Disponible en https://bit.ly/3vVhn8h. 
Riestra, Sebastián (2019). «Algunas consideraciones sobre las acciones de impugnación contra la resolución de calificación ambiental ante la garantía de la tutela judicial efectiva». En Juan Carlos Ferrada Bórquez, Andrés Bordalí Salamanca y Magdalena Prieto Pradenas (coords.), La justicia ambiental ante la jurisprudencia. Actos de las II Jornadas de Justicia Ambiental (pp. 33-52). Santiago: Ediciones Der.

Soто, Pablo (2016). «Sanciones administrativas como medidas de cumplimiento del Derecho: un enfoque funcional y responsivo aplicado al régimen sancionatorio ambiental». Ius et Praxis, 22 (2): 189-226. Disponible en https://bit.ly/2Uayigp.

PHILlips, Jaime (2020). La protección de expectativas en el derecho administrativo chileno. Una propuesta para la aplicación del principio de protección de la confianza. Valencia: Tirant lo Blanch.

Pinilla, Francisco (2014). «El deber de sometimiento al procedimiento especial como limitación al recurso de protección ambiental», Revista de Derecho (Universidad Austral de Chile), 27 (2): 291-294. Disponible en https://bit.ly/3gYeJdq.

VAldivia, José Miguel (2009). «Sobre la nulidad en derecho público». En Jaime Arancibia Mattar y José Ignacio Martínez Estay (editores), La primacía de la persona: Estudios en homenaje al profesor Eduardo Soto Kloss (pp. 865-885) Santiago: Legal Publishing Chile.

-. (2018). Manual de Derecho Administrativo. Valencia: Tirant lo Blanch.

Vergara Blanco, Alejandro (2005). «Eficacia derogatoria y supletoria de la ley de bases de los procedimientos administrativos». En Acto y procedimiento administrativo. Actas de las Segundas Jornadas de Derecho Administrativo (pp. 31-47). Valparaíso: Ediciones Universitarias de Valparaíso.

ZÚÑIGA, Francisco (2015). «A propósito de la «agonía» o «muerte» del recurso de protección ambiental». Revista de Derecho. Escuela de Posgrado, 7: 15-42. DOI: 10.5354/0719-5516.2015.37262.

\section{Agradecimientos}

Agradezco la colaboración de mi ayudante Jirhé Miranda en esta investigación. Asimismo, le doy las gracias a María Luisa Baltra, Jaime Arancibia y Cristóbal Aguilera, por sus comentarios; y a Jorge Femenías y a Edesio Carrasco por el tiempo que me destinaron para conversar de estos temas. Todos los posibles errores son mi responsabilidad. Por último, mi mayor gratitud es para mi hermana Melania que me recibió en su casa para escribir gran parte de este trabajo.

\section{Sobre el autor}

Jaime Phillips Letelier es doctor en Derecho. Profesor de Derecho Administrativo de la Universidad Finis Terrae. Su correo electrónico es jphillips@uft.cl. (D) https:// orcid.org/0000-0002-4054-3187. 
La Revista de Derecho Ambiental, del Centro de Derecho Ambiental de la Facultad de Derecho de la Universidad de Chile, es un espacio de exposición y análisis en el plano académico del derecho ambiental. Su contenido se presenta a través de doctrina, jurisprudencia y recensiones, y aborda diversas materias relacionadas con la gestión, institucionalidad y herramientas de protección ambiental y desarrollo sustentable. Se presentan artículos de diferentes autores y autoras en los que se analizan y abordan casos y temas jurídico-ambientales de creciente interés y actualidad.

\author{
DIRECTORA \\ Valentina Durán Medina \\ EDITORES \\ Jorge Ossandón Rosales \\ y Antonio Pulgar Martínez \\ SITIO WEB \\ revistaderechoambiental.uchile.cl \\ CORREO ELECTRÓNICO \\ revistada@derecho.uchile.cl \\ LICENCIA DE ESTE ARTÍ́CULO \\ Creative Commons Atribución Compartir Igual 4.o Internacional
}

La edición de textos, el diseño editorial

y la conversión a formatos electrónicos de este artículo

estuvieron a cargo de Tipográfica

(www.tipografica.io) 